\title{
Government Reorganization in the ICT Sector: Analysis of Multi- Level Factors from the Case of South Korea
}

\author{
Jisung Yoo ${ }^{\mathrm{a}}$, Koomin $\mathrm{Kim}^{\mathrm{b}}$, Jun Houng Kim ${ }^{\mathrm{c}, *}$ \\ ${ }^{a}$ College of Liberal Arts, Konkuk University Glocal Campus, \#204 Bld. K3, Konkuk Univ. 268 Chungwon-daero Chungju-si \\ Chungcheongbuk-do, 27478, Republic of Korea \\ ${ }^{b}$ Division of Public Policy, Geumgang University. 522, Sangwol-ro, Sangwol-myeon, Nonsan-si, Chungcheongnam-do, Republic of Korea \\ ${ }^{c}$ Division of Government Innovation Research, Korea Institute of Public Administration, 235 Jinheung-ro, Seoul, 03367, Republic of Korea \\ Corresponding author: ${ }^{*}$ jhk9238@kipa.re.kr
}

\begin{abstract}
Governments around the world have invested a great deal of time and energy to reform their administrative structures for increasing public officials' efficiency in internal affairs and improving citizens' satisfaction on public service. The literature on government reorganization, consisting mostly of in-depth case studies on the influential factors of government reorganization through a small-N sample of countries, has contributed to understanding the essence of government reorganization. This study raises its limitations and the necessity of follow-up studies examining the influential factors of demands and needs for government reorganization for diagnosis and prediction purposes through a large-N sample of individuals. In this vein, this study aims to perform logistic analysis to investigate the factors influencing the perceptions of survey respondents (i.e., the general public and government officials) on the need for government reorganization based on information and communications technology (ICT) in the Korean public sector. According to research findings, "possibility of conflict between security and smart work" and "urgency of responses to AI development" are associated with an increase in the perceived necessity to reorganize the ICT sector. On the other hand, "organizational amalgamation by integrating government-affiliated institutes" and "policy direction in the mobile era" are associated with a decrease in the perceived necessity to reorganize the ICT sector. These research findings suggest that scholars and practitioners need to consider multi-level factors of government reorganization when they conceive, design, adopt, and implement the restructuring of ICT-sector agencies.
\end{abstract}

Keywords - Government reorganization; information and communications technology; ICT sector; South Korea.

\section{INTRODUCTION}

Governments worldwide continuously invest considerable time and energy in reform efforts to increase efficiency and improve citizens' satisfaction with the public service provided by government agencies. In the past few decades, technological advances have provided a vast array of new means of faster and more efficient communication over distances, enabling government agencies to perform their functions more efficiently. Such technologies are referred to as information and communications technology (ICT), an extension of the term information technology (IT), and communication technologies. For example, ICT allows people to communicate in real-time with others in different locations through technologies such as the Internet, wireless networks, cell phones, and other communication mediums [1] [2]. In the public sector, ICT can enable and empower governmental reform by integrating people, governmental processes, information, and technology to increase the efficiency of providing government services. The advantages of staying abreast of and employing technological advances have been identified as increasing the efficiency of government operations, strengthening democracy, enhancing transparency in government, and providing better services to citizens [3].

Authorized by the Prime Minister of South Korea, a survey was conducted in 2017 to diagnose the function of the ICT government organization and derive an effective reorganization plan and alternatives for ensuring efficient public administration in the future. The survey, "Recognition Survey on Redesigning National Informatization Organization in Response to Changes in the Information Technology Paradigm," was developed and administered by the Korea Institute of Public Administration (KIPA), a government-sponsored research institute responsible for 
research on current, as well as historical, issues. The survey examined the perceptions of the public, including government officials, on the need for redesigning government organizations in South Korea based on changes in IT. Survey questions pertained to the respondents' knowledge of information technology and their opinions about whether the government needs to be reorganized according to the current changes in the IT paradigm.

The purpose of the current study is to investigate the factors influencing the perceptions of the general public and government officials on restructuring government organizations based on ICT in the South Korean public sector. More specifically, this study performed a logistic analysis to examine the survey items that asked respondents to rate the extent to which they thought there was a problem with certain factors that could influence the implementation of ICT policies and the urgency of the government's response address the problems. As the leading independent variables, the influential factors were categorized as individual and group factors, organizational factors, environmental factors, and information technology factors. The dependent variable was the respondents' perceptions of the need for restructuring government organizations based on the current shift in the IT paradigm in the public sector. The literature review related to theory and research on government reorganization shows below.

\section{A. Explaining Government Reorganization}

Government reorganization is one of the most shared activities of modern governments around the world. Governments worldwide have invested a great deal of time and energy to reform their administrative structures to increase public officials' efficiency in internal affairs and improve citizens' satisfaction with public service [4]. In general, government reorganization is understood as intended changes in the administrative structure of government organizations [5], [6]. Government reorganization should involve an apparent change in government structure, such as behaviors, roles, and relationships of many people. On the other hand, government reorganization does not include changes in programs that do not modify administrative structure significantly. Also, government reorganization does not encompass routine changes, changes caused accidentally, and minor changes to which the organization can adapt itself right away.

Government reorganization takes many forms according to the demands and needs of a specific country in a specific period. These different forms of government reorganization can be classified as (1) eliminating agency, (2) shifting agency from one department to another or shifting status from one organizational category to another, (3) combining two or more agencies into one, or dividing agency into two or more parts, and (4) adding major agency functions or subtracting from agency functions [5], [7]. Many agencies sometimes go through two or more forms of government reorganization in the long term [8]. For example, many agencies established to deal with the Great Depression in the United States were merged in 1939. After a decade of the merge, many of them disappeared after struggling with several government reorganizations.

There are contrasting views on whether government reorganization brings about expected benefits in public officials' efficiency in internal affairs and citizens' satisfaction with public service. On the one hand, proponents of government reorganization argue that the reorganization results in streamlining by eliminating redundancy, resulting in more exceptional efficient performance [5]. On the other hand, opponents of government reorganization claim that the reorganization often has significant unintended negative consequences on the efficient performance of government [4]. Also, they argue that government reorganization efforts sometimes seem to be proposed as fad and fashion but the same government reorganization remedies are proposed regardless of the pre-existing structures of the government.

Governments around the world tend to reorganize the ICTsector agencies frequently to deal with the rapid creation, development, and convergence of ICT. South Korean government reorganization in the ICT industry sector particularly stands out regarding the number of reorganizations and controversies in each reorganization [9]. In 1994, the conflict between the Ministry of Communication and the Ministry of Commerce and Industry over the ICT industry sector was accelerated, and these agencies' ICT industry affairs were transferred to the newly established Ministry of Information Communication (MIC). Afterward, the conflict between the MIC and the Ministry of Commerce Industry and Energy (MCIE) recurred due to controversy on the role of government in the rapidly growing ICT industry. As a result, the MIC was dissolved in 2008, and ICT industry affairs were transferred to the MCIE. However, concerns about the absence of a control tower in the ICT industry sector were raised, and the ICT industry affairs were transferred to the Ministry of Science, ICT and Future Planning, newly established in 2013. Currently, the Ministry of Science and ICT, newly established in 2017, takes charge of ICT industry affairs.

\section{B. Determinants of Government Reorganization}

What are the driving forces of government reorganization? According to the government reorganization literature, the determinants of government reorganization can be classified into (1) individual and group factors, (2) organizational factors, (3) environmental factors, and (4) information technology factors. First, individual and group factors encompass individual behavior and interaction among a handful of individuals, which influences government reorganization [4], [10], [11]. According to this approach, individuals such as politicians and bureaucrats with goals and capacities have a particular final state when seeking government reorganization. These individuals are powerful sufficiently to attain the reform adopted and enforced. This approach focuses on the perceived problems and motivations of individuals (and the groups in which they are affiliated) and seeks to understand why government reorganization decisions are taken, given their problems and motivations.

Second, organizational factors are composed of organizational characteristics, processes, structures, and relations that influence government reorganization [12], [13] [14]. Examples of organizational factors are leadership, organizational structure, and size of administrative resources. According to this approach, organizational capability, understood as an ability to mobilize and deploy administrative resources, is a core factor leading to government reorganization. Among various forms of organizational capabilities, organizational IT capability is understood as an ability to mobilize and deploy IT-based resources, or the 
organization's ability for planning and cost-effective operations satisfies the necessary condition for government reorganization and stimulates needs for government reorganization.

Third, environmental factors consist of institutional, cultural, and contextual factors operating in organizations that influence government reorganization [4], [15], [16]. According to this approach, government reorganization that occurs is a function of the relationship between the government's structure and its environment. The environment encompasses laws and norms that promote or constrain individuals' behavior and the economic and social context (e.g., economic conditions and demographic characteristics). While individual and group factors highlight actors' motivation and intention as the direct driving force of government reorganization, environmental factors emphasize that any individuals appear to transmit environmental forces to decide on government reorganization.

Fourth, information technology factors include technological improvements and information technology quality or characteristics that influence government reorganization [17], [18], [19]. According to this approach, technology is autonomous upon social components (e.g., individuals, organizations, institutions, cultures). In other words, technological advancement or information technology characteristics influence government reorganization and do not transmit social components to cause government reorganization. For the full actualization of the potential value of technological improvement, technological components such as availability of technological infrastructure, technological compatibility, and information security or protection are crucial to the occurrence of government reorganization.

\section{Critique of Theory and Research on Government Reorganization}

Although the literature on government reorganization has contributed to understanding the essence of government reorganization, this study raises its limitations and the necessity of follow-up studies. First, empirical studies on government reorganization tend to focus on the in-depth analysis of past small-N government reorganization cases in a retrospective manner. For instance, Rhodes analyzed the influential factors of government reorganization through English and Danish reform cases [20]. Similarly, Bezes and Parrado revealed the determinants of government reorganization through French and Spanish reform cases [21]. On the other hand, few empirical studies have diagnosed and predicted demands and needs for government reorganization through large-N cases of individuals' perception in a prospective manner. Since government reorganization is one of the most frequent and recurring activities of contemporary governments, studies are needed to examine the influential factors of demands and needs for government reorganization for diagnosis and prediction purposes through a large- $\mathrm{N}$ sample of individuals.

Second, theoretical and empirical studies on government reorganization highlight the environmental factors as a determinant of government reorganization. For instance, Bezes et al. revealed that environmental factors such as political regime, diffusion and learning from foreign countries, and financial crisis are the crucial factors leading to government reorganization in Norway and France [22]. Similarly, Painter and Peters asserted that environmental factors such as Europeanization, globalization, tradition, and social pressure are the main factors leading to government reorganization in European countries [23]. As noted previously, however, government reorganization depends on environmental factors and depends on individual and group factors, organizational factors, and information technology factors. Therefore, further research is needed for analyzing the influential multi-level factors of demands and needs for government reorganization in a comprehensive and integrative manner.

Third, empirical studies on government reorganization tend to select a country as a unit of analysis and conduct an indepth case study examining the actual occurrence or status of government reorganization in terms of methodology. For instance, Rhodes and Bezes et al. conducted an in-depth case study of two European countries to reveal influential factors on government reorganization [20], [22]. Even though the indepth case study provided insight to scholars and practitioners on the essence of government reorganization, the actual occurrence or status is not likely to be the same as individuals' perception concerning government reorganization. It is also expected that the research findings derived from a small-N sample of countries do not capture the other significant research findings that can be derived from a large- $\mathrm{N}$ sample of individuals because of constraints on case-centric research. Therefore, further research adopting a variable-centric strategy with a large $\mathrm{N}$ sample of individuals is needed to investigate the influential factors of demands and needs for government reorganization.

In this vein, this study aims to perform logistic analysis to investigate the factors influencing the perceptions of survey respondents (i.e., the general public and government officials) on the need for government reorganization based on ICT in the South Korean public sector. More specifically, this study focuses on the survey items that asked respondents to rate how they thought there was a problem with specific factors that could influence the implementation of ICT policies and the urgency of the government's response to address the problems. As the main independent variables, the influential factors were categorized as individual and group factors, organizational factors, environmental factors, and information technology factors. The dependent variable was the respondents' perceptions of government reorganization based on the current shift in the IT paradigm in the public sector.

This paper begins with a review of the literature on the factors influencing the need for restructuring government organizations based on ICT. The next section discusses the research design, including the theoretical framework of this study, data, measurement, and methodology. Then, the research results are presented, followed by a discussion and interpretation of the results. The final section of this paper, the conclusion, provides practical and theoretical implications, implications for future research, and limitations.

\section{MATERIAL AND METHOD}

\section{A. Research Model}

Based on the theoretical background and literature review, Figure 1 provides the research model for this study. Perceptions of the general public and government officials on reorganizing the ICT sector depend on individual and group factors, organizational factors, environmental factors, information technology factors, and socioeconomic status. 


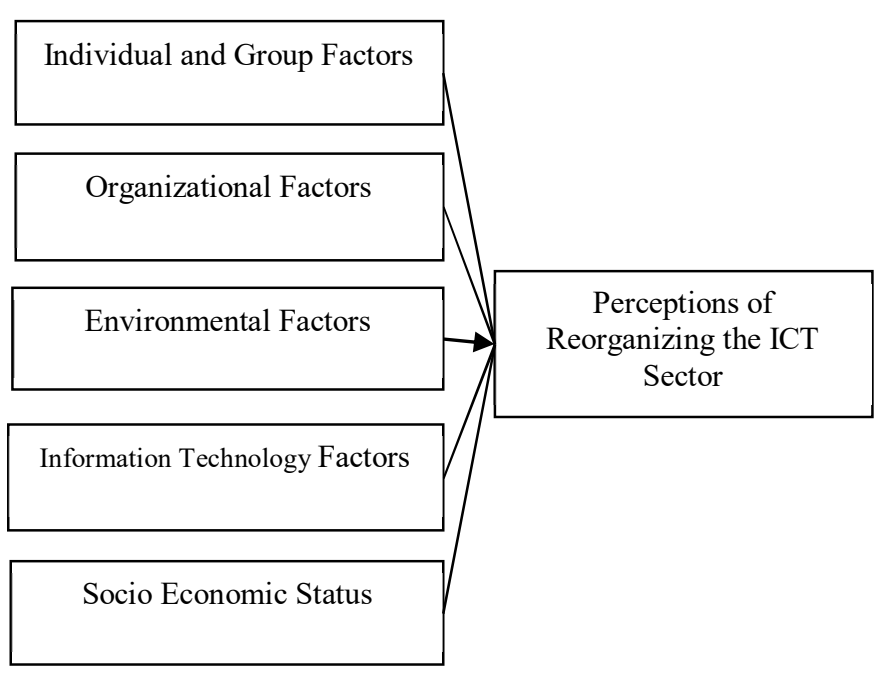

Fig. 1 Research model

\section{B. Data and Measurement}

Data were drawn from a survey conducted by the Korea Institute of Public Administration in 2017 related to "the measures of the reorganization in the ICT sector to cope with the changes in ICT paradigm." The survey items asked respondents to rate the extent to which they thought there was a problem with certain factors that could influence the implementation of ICT policies and the urgency of the government's response to address the problems. The dependent variable, respondents' perceptions on the need for restructuring government organizations based on the current shift in the IT paradigm in the public sector, was measured as a binary variable, with 1 indicating the perception that reorganization is needed, and the value of 2 indicating that reorganization is not needed.

As the main independent variables, the influential factors were categorized as individual and group factors, organizational factors, environmental factors, and information technology factors. Individual and group factors were organized under the expertise of government officials in job rotation positions, ability to communicate with government-affiliated institutes and national leaders' interest in national informatization and e-government.

Organizational factors were composed of 11 categories: (1) the ICT-specific ministry's experience to push forward national informatization policy, (2) the status of e-government-related divisions within ministries, (3) the ability to handle conflicts among informatization-related ministries, (4) efforts for administrative reform through information technology, (5) the possibility of conflict between security and smart work, (6) organizational capacity to respond to the rapid development of ICT technologies, (7) management of the ICT project budget, (8) efficient operation of ICT-related funds, (9) capacity to deal with jurisdictional dispute on ICT-related projects, (10) reallocation of government-affiliated institutes' functions following the relocation of public institutions, and (11) organizational amalgamation by integrating government-affiliated institutes (welfare, wage, and others.).

Environmental factors included three categories: policy direction in the mobile era, confusion about establishing national informatization strategy due to confusion between informatization and e-government, and authoritative organizational culture. Information technology factors were categorized under the topics of the urgency of responses to AI development, the urgency of responses to Big Data development, and the urgency of responses to loT development. Socioeconomic status factors included gender, education, and age.

All of the independent variables other than socioeconomic status were measured on a 5-point Likert scale ranging from 1 to 5 , with 1 indicating "totally unproblematic" and 5 indicating "very problematic." For socioeconomic status, gender was measured as a binary variable, with 1 for male and 2 for female. Education was measured as a categorical variable, consisting of 5 dimensions $(1=$ high school graduates, $2=$ two-year college graduates, 3=university graduates, $4=$ graduate school students, and $5=$ graduates of a graduate school). Age was measured as a continuous variable, with respondents providing their actual age.

\section{Methodology}

This study employed logistic regression analysis as the appropriate method to consider the dichotomous (binary) nature of the dependent variable. Specifically, logistic regression describes data and explains the relationship between the dependent variable and the independent variables. Also, the robust standard error was applied for the consideration of heteroscedasticity.

\section{RESULTS AND DISCUSSION}

Table 1 presents the descriptive statistics of the variables included in this study. A total of 516 respondents were included in the analysis. Among them, 213 responses were from the general public, while 303 responses were from public officials ${ }^{1}$.

Table 2 shows the results of the logistic regression analysis. The analysis of the model with all respondents (i.e., the general public and public officials) revealed that the organizational factor "possibility of conflict between security and smart work" was statistically significant and the direction of the relationship was negative. This result indicates that the more the general public and public officials perceive the conflict as a problematic issue, the more likely they perceive that reorganizing the ICT sector is necessary. On the other hand, the organizational factor "organizational amalgamation by integrating government-affiliated institutes" is estimated to have a statistically significant positive relationship with reorganizing the ICT sector. This result indicates that if the respondents perceive the organizational amalgamation as problematic, they are less likely to support reorganizing the ICT sector. The coefficient of "policy direction in the mobile era" is significant due to environmental factors. The direction of the relationship is positive, indicating that the more they regard policy direction as problematic, the more likely they oppose reorganizing the ICT sector.

Regarding the information technology factors, "urgency of responses to AI development" was found to have a statistically significant negative relationship with reorganizing the ICT sector. This result implies that the more the general public and public officials perceive an urgency of responses to AI development as a problematic issue, the more likely they advocate for reorganizing the ICT sector. Among the socioeconomic status control variables, gender was found to have a statistically significant negative relationship with reorganizing the ICT sector, and this result indicates that female respondents were more supportive in reorganizing the ICT sector than male respondents.

\footnotetext{
${ }^{1}$ We also conducted correlation analysis and results show that collinearity issues are not present.
} 
TABLE I

DESCRIPTIVE STATISTICS RESULTS

\begin{tabular}{|c|c|c|c|c|c|c|c|c|c|c|}
\hline \multirow{2}{*}{ Variable Type } & \multirow{2}{*}{ Variable } & \multicolumn{3}{|c|}{ All Respondents } & \multicolumn{3}{|c|}{ General Public } & \multicolumn{3}{|c|}{ Public Officials } \\
\hline & & $\mathbf{N}$ & $\mathbf{M}$ & SD & $\mathbf{N}$ & $\mathbf{M}$ & SD & $\mathbf{N}$ & $\mathbf{M}$ & SD \\
\hline Dependent Variable & Government reorganization in the ICT sector & 516 & 0.091 & 0.235 & 213 & 0.062 & 0.198 & 303 & 0.112 & 0.256 \\
\hline \multirow{3}{*}{$\begin{array}{l}\text { Individual and group } \\
\text { factors }\end{array}$} & The expertise of government officials in job rotation positions & 516 & 1.251 & 0.282 & 213 & 1.230 & 0.290 & 303 & 1.266 & 0.276 \\
\hline & Ability to communicate with government-affiliated institutes & 516 & 1.222 & 0.290 & 213 & 1.244 & 0.305 & 303 & 1.207 & 0.280 \\
\hline & National leaders' interest in national informatization and e-government & 516 & 1.176 & 0.304 & 213 & 1.194 & 0.305 & 303 & 1.164 & 0.304 \\
\hline \multirow[t]{11}{*}{ Organizational factors } & $\begin{array}{l}\text { The ICT-specific ministry's experience to push forward national informatization } \\
\text { policy }\end{array}$ & 516 & 1.116 & 0.300 & 213 & 1.154 & 0.269 & 303 & 1.090 & 0.318 \\
\hline & The status of e-government-related divisions within ministries & 516 & 1.166 & 0.280 & 213 & 1.187 & 0.263 & 303 & 1.152 & 0.290 \\
\hline & The ability to handle conflicts among informatization-related ministries & 516 & 1.207 & 0.282 & 213 & 1.214 & 0.284 & 303 & 1.203 & 0.281 \\
\hline & Efforts for administrative reform through information technology & 516 & 1.116 & 0.327 & 213 & 1.176 & 0.313 & 303 & 1.075 & 0.330 \\
\hline & The possibility of conflict between security and smart work & 516 & 1.181 & 0.294 & 213 & 1.196 & 0.281 & 303 & 1.171 & 0.302 \\
\hline & Organizational capacity to respond to rapid development of ICT technologies & 516 & 1.228 & 0.277 & 213 & 1.232 & 0.271 & 303 & 1.225 & 0.282 \\
\hline & Management of ICT project budget & 516 & 1.204 & 0.277 & 213 & 1.215 & 0.276 & 303 & 1.196 & 0.278 \\
\hline & Efficient operation of ICT-related fund & 516 & 1.206 & 0.266 & 213 & 1.210 & 0.280 & 303 & 1.204 & 0.255 \\
\hline & Capacity to deal with jurisdictional dispute on ICT-related projects & 516 & 1.226 & 0.275 & 213 & 1.210 & 0.288 & 303 & 1.236 & 0.265 \\
\hline & $\begin{array}{l}\text { Reallocation of government-affiliated institutes' functions following the relocation of } \\
\text { public institutions }\end{array}$ & 516 & 1.220 & 0.298 & 213 & 1.222 & 0.299 & 303 & 1.219 & 0.298 \\
\hline & $\begin{array}{l}\text { Organizational amalgamation by integrating government-affiliated institutes (welfare, } \\
\text { wage, etc.) }\end{array}$ & 516 & 1.201 & 0.294 & 213 & 1.189 & 0.315 & 303 & 1.209 & 0.279 \\
\hline \multirow[t]{3}{*}{ Environmental factors } & Policy direction in the mobile era & 516 & 1.125 & 0.298 & 213 & 1.165 & 0.267 & 303 & 1.098 & 0.315 \\
\hline & $\begin{array}{l}\text { Confusion about establishing national informatization strategy due to confusion } \\
\text { between informatization and e-government }\end{array}$ & 516 & 1.186 & 0.292 & 213 & 1.205 & 0.301 & 303 & 1.173 & 0.285 \\
\hline & Authoritative organizational culture & 516 & 1.292 & 0.293 & 213 & 1.304 & 0.291 & 303 & 1.283 & 0.295 \\
\hline \multirow{3}{*}{$\begin{array}{l}\text { Information } \\
\text { technology factors }\end{array}$} & Urgency of responses to $\mathrm{AI}$ development & 516 & 3.909 & 1.040 & 213 & 3.610 & 1.020 & 303 & 4.119 & 1.003 \\
\hline & Urgency of responses to Big Data development & 516 & 3.798 & 1.033 & 213 & 3.493 & 0.979 & 303 & 4.013 & 1.016 \\
\hline & Urgency of responses to loT development & 516 & 3.709 & 1.007 & 213 & 3.498 & 0.989 & 303 & 3.858 & 0.995 \\
\hline \multirow[t]{3}{*}{ SES } & Gender & 516 & 0.265 & 0.337 & 213 & 0.338 & 0.347 & 303 & 0.213 & 0.320 \\
\hline & Education & 516 & 1.159 & 0.425 & 213 & 0.927 & 0.483 & 303 & 1.321 & 0.284 \\
\hline & Age & 516 & 1.183 & 0.320 & 213 & 1.207 & 0.348 & 303 & 1.166 & 0.299 \\
\hline
\end{tabular}

Note: $\mathrm{M}=$ Mean $. \mathrm{SD}=$ Standard Deviation. 
TABLE II

LOGISTIC REGRESSION ANALYSIS RESULTS

\begin{tabular}{|c|c|c|c|c|c|c|c|}
\hline \multirow{2}{*}{ Type } & \multirow[t]{2}{*}{ Variable } & \multicolumn{2}{|c|}{$\begin{array}{c}\text { All } \\
\text { Respondents }\end{array}$} & \multicolumn{2}{|c|}{ General Public } & \multicolumn{2}{|c|}{ Public Officials } \\
\hline & & B & S.E. & B & S.E. & B & S.E. \\
\hline \multirow{8}{*}{$\begin{array}{l}\text { Individual } \\
\text { and group } \\
\text { factors }\end{array}$} & The expertise of government officials in job rotation positions & -.164 & .596 & 1.102 & 1.189 & -1.037 & .744 \\
\hline & Ability to communicate with government-affiliated institutes & .828 & .569 & -.686 & 1.766 & $1.216 *$ & .715 \\
\hline & National leaders' interest in national informatization and e-government & .206 & .525 & .762 & 1.068 & .088 & .669 \\
\hline & The ICT-specific ministry's experience to push forward national informatization policy & -.506 & .517 & -.410 & 1.045 & -.275 & .699 \\
\hline & The status of e-government-related divisions within ministries & -.544 & .575 & 1.480 & 1.313 & -1.052 & .751 \\
\hline & The ability to handle conflicts among informatization-related ministries & -.711 & .613 & -.932 & 1.001 & -.577 & .741 \\
\hline & Efforts for administrative reform through information technology & -.568 & .447 & $-1.973 * *$ & .822 & -.573 & .628 \\
\hline & The possibility of conflict between security and smart work & $-1.044 *$ & .626 & $-3.430 * *$ & 1.511 & -.838 & .774 \\
\hline \multirow{7}{*}{$\begin{array}{l}\text { Organization } \\
\text { al factors }\end{array}$} & Organizational capacity to respond to rapid development of ICT technologies & -.190 & .800 & $-2.675 *$ & 1.433 & .501 & .983 \\
\hline & Management of ICT project budget & -.272 & .646 & 1.833 & 1.163 & -.908 & .928 \\
\hline & Efficient operation of ICT-related fund & .401 & .871 & 1.700 & 1.506 & .426 & 1.168 \\
\hline & Capacity to deal with jurisdictional dispute on ICT-related projects & -.768 & .711 & -.397 & 1.681 & -.725 & .949 \\
\hline & Reallocation of government-affiliated institutes' functions following the relocation of public institutions & -.679 & .598 & $-2.898 *$ & 1.643 & -.040 & .785 \\
\hline & Organizational amalgamation by integrating government-affiliated institutes (welfare, wage, etc.) & 1.136* & .645 & 2.197 & 1.429 & 1.179 & .823 \\
\hline & Policy direction in the mobile era & * 1.486* & .588 & $3.702 * *$ & 1.459 & $\underset{* *}{1.533}$ & .714 \\
\hline \multirow{2}{*}{$\begin{array}{l}\text { Environment } \\
\text { al factors }\end{array}$} & $\begin{array}{l}\text { Confusion about establishing national informatization strategy due to confusion between informatization and e- } \\
\text { government }\end{array}$ & .709 & .675 & 1.401 & 1.564 & .503 & .815 \\
\hline & Authoritative organizational culture & .494 & .676 & 1.630 & 1.537 & -.145 & .688 \\
\hline Information & Urgency of responses to AI development & $-.385 *$ & .163 & $-.967 * * *$ & .273 & -.185 & .208 \\
\hline technology & Urgency of responses to Big Data development & .240 & .191 & .463 & .394 & .160 & .213 \\
\hline \multirow[t]{5}{*}{ factors } & Urgency of responses to loT development & -.196 & .166 & -.497 & .409 & -.230 & .194 \\
\hline & Gender & $-1.062 *$ & .469 & $-1.881 *$ & .973 & -.454 & .610 \\
\hline & Education & $.743^{*}$ & .441 & .054 & .772 & .435 & .722 \\
\hline & Age & .031 & .442 & .235 & .905 & .341 & .683 \\
\hline & constant & -1.215 & 1.146 & -2.218 & 1.920 & -.758 & 1.569 \\
\hline \multirow[t]{5}{*}{ SES } & $\mathrm{N}$ & 516 & & 213 & & 303 & \\
\hline & Wald chi2(23) & 37.330 & & 35.720 & & 26.170 & \\
\hline & Prob > chi 2 & .030 & & .044 & & .293 & \\
\hline & Pseudo $\mathrm{R}^{2}$ & .093 & & .270 & & .082 & \\
\hline & Log pseudolikelihood & -182.378 & & -46.726 & & -123.147 & \\
\hline
\end{tabular}


Turning to the analysis of the responses from the general public, the organizational factor "efforts for administrative reform through information technology" was statistically significant and the direction of the relationship was negative. If the public perceives that efforts for administrative reform through information technology is a problematic issue, this increases the likelihood that they would support reorganizing the ICT sector. The organizational factor "the possibility of conflict between security and smart work" was statistically significant, and the direction of the relationship was negative. This result provides evidence that the general public is more likely to support the reorganization of the ICT sector when they perceive the possibility of conflict between security and smart work as a problematic issue. Also, there is a statistically significant positive relationship between organizational capacity to respond to the rapid development of ICT technologies and the reorganization of the ICT sector. Thus, the more the public regards the government's capacity to respond to the rapid development of ICT technologies as problematic, the more likely they oppose reorganizing the ICT sector.

Further, the coefficient of "reallocation of governmentaffiliated institutes' functions following the relocation of public institutions" is statistically significant and the direction of the relationship is negative, indicating that the public is more likely to support the reorganization of the ICT sector when they perceive that reallocation of government-affiliated institutes' functions following the relocation of public institutions is a problematic issue. Results from environmental and information technology factors reveal that the coefficient of "policy direction in the mobile era" is significant and positive, indicating that the more the public considers policy direction as problematic, the more likely they oppose reorganizing the ICT sector. Meanwhile, the coefficient of "urgency of responses to AI development" reveals a statistically significant negative relationship, suggesting that the more the public perceives an urgency of responses to AI development as problematic, the more likely they support reorganizing the ICT sector. Concerning the socioeconomic status control variables, gender was found to have a statistically significant negative relationship with reorganizing the ICT sector, indicating that female respondents show more support for reorganizing the ICT sector than male respondents.

Lastly, a model that includes public officials reveals that individual and group factors, including the ability to communicate with government-affiliated institutes, have a statistically significant positive relationship with reorganization in the ICT sector. This result implies that if public officials regard the ability to communicate with government-affiliated institutes as problematic, they are less likely to support reorganizing the ICT sector. Regarding the environmental factor, the coefficient of policy direction in the mobile era is significant and positive, and thus it is more likely that public officials oppose reorganizing the ICT sector when they consider policy direction as problematic.

Comparing across models, the variable policy direction in the mobile era commonly affects the perception of the reorganization of the ICT sector. The coefficient of policy direction in the mobile era is significant, and the direction of the relationship is positive. This result suggests that both people and public officials consider policy direction as problematic, and it is more likely that they oppose reorganizing the ICT sector. On the contrary, the perceptions of people, which include efforts for administrative reform through information technology, the possibility of conflict between security and smart work, organizational capacity to respond to the rapid development of ICT technologies, reallocation of government-affiliated institutes' functions following the relocation of public institutions, the urgency of responses to AI development and gender have significant effects on the perception of reorganizing the ICT sector. In contrast, the perceptions of public officials, which involves the communication capacity with subordinate agencies have a significant impact on the perception of reorganizing the ICT sector.

\section{CONCLUSION}

The current study aimed to investigate the factors influencing the perceptions of the general public and government officials on the need to restructure government organizations based on Information Communication Technology (ICT) in the South Korean public sector. Logistic regression analysis was employed to examine responses to survey items that asked participants to rate the extent to which they thought there was a problem with certain factors that could influence the implementation of ICT policies and the urgency of the government's response to address the problems. The influential factors, the independent variables in this study, were categorized as individual and group factors, organizational factors, environmental factors, and information technology factors. The dependent variable was the respondents' perceptions on the need for restructuring government organizations based on the current shift in the IT paradigm in the public sector.

According to the research findings, the organizational factor "the possibility of conflict between security and smart work" and the information technology factor "the urgency of responses to AI development" are associated with an increase in the perceived necessity to reorganize the ICT sector. This finding suggests that the more citizens and public officials perceive the conflict between security and smart work as a problematic issue and the more they perceive an urgency of responses to AI development as a problematic issue, the more likely they regard reorganizing the ICT sector as necessary. On the other hand, the organizational factor "organizational amalgamation by integrating government-affiliated institutes" and the environmental factor "policy direction in the mobile era" is associated with a decrease in the perceived necessity to reorganize the ICT sector. These findings suggest that the more they regard organizational amalgamation by integrating government-affiliated institutes as problematic and the more they regard policy direction in the mobile era as problematic, the more likely they oppose reorganizing the ICT sector.

The research findings have several theoretical and practical implications. First, this study can inform policymakers of specific directions in government reorganization by examining the perceptions of the general public and public officials on the need for government reorganization based on ICT. Second, the research findings from this study can contribute to the literature in that this study applied a new conceptual framework to government reorganization in the 
ICT sector for theoretical discussion on government reorganization. Third, in addition to the perceptions of public officials on the need for government reorganization revealed by previous research, the current study revealed the perceptions of the general public on the need for government reorganization and identified the significant relationships between influential factors and their perceptions. These findings not only contribute to the literature but can also guide researchers in developing further research. Fourth, this study contributes to the existing literature by examining the influence of multi-dimensional factors, including individual and group factors, organizational factors, environmental factors, and information technology factors. It is different from the existing literature that focused mostly on environmental factors as having a significant influence on government reorganization.

This study is not without limitations. First, this research analyzes data from the year 2017. For a further and more accurate investigation, analysis of longitudinal data is needed for future research. Secondly, the sample size utilized for this study was limited to 516 survey respondents (213 general public and 303 government officials). Future research with larger sample size is required for a more comprehensive and accurate analysis.

\section{ACKNOWLEDGMENT}

This paper is supported by the National Research Foundation of Korea Grant from the Korean Government NRF-2017S1A3A2066084).

\section{REFERENCES}

[1] A. V. Roman, M. Van Wart, X. Wang, C. Liu, S. Kim, and A. McCarthy, "Defining e-leadership as competence in ICT-mediated communications: An exploratory assessment, "Public Administration Review, vol. 79, no. 6, pp. 853-866, 2019.

[2] C. E. Sunday and C. C. E. Vera, "Examining information and communication technology (ICT) adoption in SMEs: A dynamic capabilities approach,"Journal of Enterprise Information Management, vol. 31, no. 2, pp. 338-356, 2018.

[3] S. Lee-Geiller and T. D. Lee, "Using government websites to enhance democratic e-governance: A conceptual model for evaluation," Government Information Quarterly, vol. 36, no. 2, pp. 208-225, 2019.

[4] B. G. Peters, "Government reorganization: A theoretical analysis," International Political Science Review, vol. 13, no. 2, pp. 199-217, 1992.
[5] C. Grafton, "The reorganization of federal agencies," Administration \& Society, vol. 10, no. 4, pp. 437-464, 1979.

[6] F. C. Mosher, Governmental Reorganizations: Cases and Commentary. Indianapolis: Bobbs-Merrill, 1967.

[7] H. C. Mansfield, "Federal executive reorganization: Thirty years of experience," Public Administration Review, vol. 29, no. 4, pp. 332345. 1969.

[8] H. Kaufman, Are Government Organizations Immortal? Washington, DC: Brookings Institution, 1976.

[9] Y. Jung, "ICT-sector reorganization in major countries and its influential factors," Modern Society and Public Administration, vol. 27, no. 4, pp. 103-145, 2017.

[10] W. Niskanen, Bureaucracy and Representative Government. Chicago: Aldine/Atherton, 1971.

[11] C. Pollitt, Manipulating the Machine: Changing the Pattern of Ministerial Departments, 1960-83. London: George Allen \& Unwin, 1984.

[12] J. L. Garnett, Reorganizing State Government: The Executive Branch. New York, NY: Routledge, 2019.

[13] T. Christensen, and P. Lægreid, An Organization Approach to Public Administration. In the Palgrave handbook of public administration and management in Europe (pp. 1087-1104). London: Palgrave Macmillan, 2018.

[14] S. Hong and N. Park, "Administrative reorganization as a signal: Bounded rationality, agency merger, and salience of policy issues," Governance, vol. 32, no. 3, pp. 421-439, 2019.

[15] L. Ma and T. Christensen, "Mapping the evolution of the central government apparatus in China," International Review of Administrative Sciences, vol. 86, no. 1, pp. 80-97, 2020.

[16] F. Iannacci, A. P. Seepma, C. De Blok, and A. Resca, "Reappraising maturity models in e-Government research: The trajectory-turning point theory," The Journal of Strategic Information Systems, vol. 28, no. 3, pp. 310-329, 2019.

[17] K. L. Kraemer, Administrative Reform and Information Technology in the Digital Society. Irvine, CA: University of California Digital Library, 2017.

[18] C. S. Chung, "From electronic government to platform government," Journal of Platform Technology, vol. 5, no. 3, pp. 3-10, 2017.

[19] I. Heo, "Government reorganization in the light of quality of democracy: South Korea," Asian Politics \& Policy, vol. 9, no. 2, pp. 202-221, 2017.

[20] R. A. Rhodes, "Traditions and public sector reform: Comparing Britain and Denmark," Scandinavian Political Studies, vol. 22, no. 4, pp. 341-370, 1999.

[21] P. Bezes and S. Parrado, "Trajectories of administrative reform: Institutions, timing and choices in France and Spain," West European Politics, vol. 36, no. 1, pp. 22-50, 2013.

[22] P. Bezes, A. L. Fimreite, P. L. Lidec, and P. Laegreid, "Understanding organizational reforms in the modern state: Specialization and integration in Norway and France," Governance, vol. 26, no. 1, pp. 147-175, 2003.

[23] M. Painter and B. G. Peters, The Analysis of Administrative Traditions. In Tradition and Public Administration (pp. 3-16). London: Palgrave Macmillan, 2010. 